\title{
High-resolution ASCAT scatterometer winds near the coast
}

\author{
Anton Verhoef, Marcos Portabella and Ad Stoffelen
}

\begin{abstract}
The EUMETSAT Ocean and Sea Ice Satellite Application Facility (OSI SAF) delivers operational wind products from the Advanced Scatterometer (ASCAT) at $25 \mathrm{~km}$ and $12.5 \mathrm{~km}$ Wind Vector Cell (WVC) spacing. In these products, based on the backscatter processing performed at EUMETSAT, data closer than $\sim 70 \mathrm{~km}(25 \mathrm{~km}$ products) or $\sim 35 \mathrm{~km}(12.5 \mathrm{~km}$ products) to the coast are flagged because of land contamination. An alternative wind product is presented here which uses a different way of averaging the full resolution backscatter measurements from ASCAT. The full resolution backscatter measurements are screened for land contamination in the coastal zone, thus allowing the construction of WVCs that follow the coast line. The implied alternative spatial averaging allows good quality winds over sea as close as $15-20 \mathrm{~km}$ to the shore.

The alternative (coastal) and nominal products are compared and the resulting winds are validated with buoy winds, both in coastal and open sea regions. In regions far away from the coast the ASCAT coastal and nominal products appear to be of identical quality, but fewer WVCs pass the quality control steps for the nominal product, indicating that the coastal product better resolves sub-WVC wind variability. In the coastal region we anticipate enhanced wind variability due to katabatic and sea breeze effects, among others. However, the quality of the coastal winds in terms of buoy wind component difference standard deviation is almost as good as for the open sea winds.
\end{abstract}

Index Terms - Wind, Sea coast, Radar scattering

\section{INTRODUCTION}

$\mathrm{T}$ HE Metop-A satellite was launched on 19 October 2006 and carries the Advanced Scatterometer (ASCAT). The instrument is a real aperture, $\mathrm{C}$ band, vertically polarized radar with three fan beam antennas pointing to the left hand side of the sub-satellite track and three fan beam antennas pointing to the right hand side. The Ocean and Sea Ice Satellite Application Facility (OSI SAF) of the European Organisation for the Exploitation of Meteorological Satellites (EUMETSAT) is responsible for the operational provision of wind products from ASCAT data. The nominal OSI SAF ASCAT level 2 wind products are based on the ASCAT level

Manuscript received June 1, 2011.

A. Verhoef and A. Stoffelen are with the Royal Netherlands Meteorological Institute (KNMI), 3732 GK De Bilt, The Netherlands (e-mail: verhoefa@knmi.nl; stoffele@knmi.nl).

M. Portabella is with the Unidad de Tecnología Marina (UTM-CSIC), 08003 Barcelona, Spain (e-mail: portabella@cmima.csic.es).

This work has been funded by EUMETSAT in the context of the Ocean and Sea Ice Satellite Application Facility.
1 products with $25 \mathrm{~km}$ and $12.5 \mathrm{~km}$ Wind Vector Cell (WVC) spacing from EUMETSAT [1], [2]. In the nominal $25 \mathrm{~km}$ product, WVCs within $70 \mathrm{~km}$ from the coast are omitted, because backscatter measurements as far as $70 \mathrm{~km}$ away from a WVC centre are used in the spatial averaging (see Fig. 1). For similar reasons, WVCs within $35 \mathrm{~km}$ from the coast are omitted in the $12.5 \mathrm{~km}$ product. See the ASCAT product guide [2] for more information on the level 1 product characteristics.

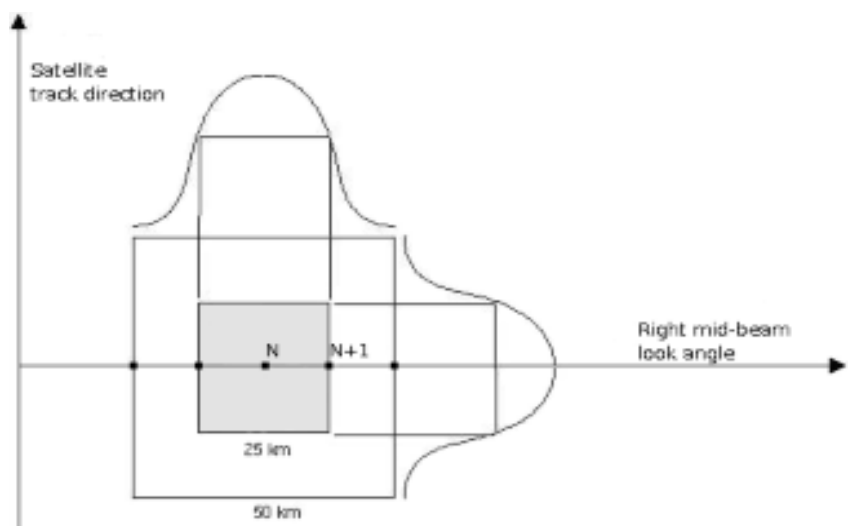

Fig. 1. Ground geometry of the spatial smoothing (Hamming filter) for $\sigma 0$ values corresponding to the right mid beam for a given WVC (node) N, for the $12.5 \mathrm{~km}$ ASCAT level 1 product (after Figure 4 of [2]).

A detailed knowledge of local wind fields near the shore is very important since they strongly affect the weather and microclimate in coastal regions. Since coastal areas are densely populated, most activity at sea occurs near the shore and sea-surface wind field information is important for a number of applications. Owen and Long [3] have computed winds nearer to the coast for QuikSCAT and in this work we will attempt to obtain ASCAT coastal winds.

In addition to the $25 \mathrm{~km}$ and $12.5 \mathrm{~km}$ level 1 (backscatter) products, a full resolution (FR) ASCAT level 1 product is also available. This product contains the individual radar backscatter values, i.e., 256 values along each antenna beam, localized on the surface of the Earth. In the FR product the data are organized along the six antenna beams rather than per WVC in the swath. The sampling of individual backscatter values along-beam is of approximately $2 \mathrm{~km}$ for mid beams and $3 \mathrm{~km}$ for fore and aft beams. The FR backscatter values represent footprints of approximately $10 \times 25 \mathrm{~km}$ of various shapes and orientations [2].

In this paper, we present and validate a new ASCAT wind product, hereafter referred as 'coastal product', which is based on the full resolution backscatter product. In Section II, the 
main characteristics of the coastal processing are presented. Different test data sets, made with different parameter settings, are used as is described in Section III. In Section IV, we assess the quality of the $12.5 \mathrm{~km}$ ASCAT coastal products by comparing the coastal winds to in situ data from moored buoys in coastal regions. Since these may be considered as local winds, they contain all wind scales and provide excellent verification of the detail and noise in scatterometer WVCmean winds. The product characteristics in non-coastal regions (more than $50 \mathrm{~km}$ from the coast) are also compared to those of the nominal $12.5 \mathrm{~km}$ product. In particular, we verify the spectral characteristics of the diverse wind products. Finally, conclusions and recommendations for future work are discussed in Section V.

\section{ASCAT COASTAL PROCESSING}

The coastal processing differs from the nominal wind products in two aspects:

(1) The Wind Vector Cell backscatter values are not averaged using a Hamming filter (Fig. 1) but using a simple box averaging. The ASCAT Wind Data Processing (AWDP) processing software reads in a $12.5 \mathrm{~km}$ level 1 nominal product and the FR product of the corresponding orbit. The nominal level 1 product swath grid is adopted for the coastal processing, such that for each WVC centre (latitude/longitude) location all FR backscatter data closer than a certain distance $R_{\max }$ from this location are simply averaged to compute new WVC $\sigma_{0}$, incidence and azimuth values. The resulting backscatter data are further processed to a wind product in the same way as is done for the nominal products.

(2) While the land contamination is assessed at WVC $\sigma_{0}$ level in the nominal products, it is assessed at each individual FR backscatter measurement in the coastal product, using a land-sea mask from the European Centre for Medium Range Weather Forecasts (ECMWF) operational model containing 400 grid points between the Equator and the Pole, i.e., at about $25 \mathrm{~km}$ spacing. A measurement land fraction is calculated using all land-sea mask grid points closer than 20 $\mathrm{km}$ from the full resolution measurement location. Every grid point found yields a land fraction (between 0 and 1). The land fraction of the measurement is calculated as the average of the grid land fractions, where each grid land fraction has a weight of $1 / r^{2}, r$ being the distance between the full resolution measurement and the model grid point. The maximum distance was set to $20 \mathrm{~km}$ in all cases. Full resolution measurements with a land fraction of more than 0.02 (i.e., $2 \%$ ) are skipped for the computation of the averaged WVC $\sigma_{0}$ value. Note that due to the rejection of land contaminated measurements, the location of the closest WVCs to the coast will be displaced in a direction away from the coast.

It can be expected that with this coastal processing, winds as close as $\sim 15 \mathrm{~km}$ from the coast can be computed. The proximity to the coast will depend on the backscatter averaging area (box size, dependent on $R_{\max }$ ) where a smaller box size may provide winds nearer to the coast and perhaps of higher resolution. On the other hand, a smaller box size will result in higher noise. In the level $1 \mathrm{~b}$ products, a Hamming window is applied in order to minimize noise (prevent aliasing), as illustrated in Fig. 1. One would expect that box averaging, e.g., averaging only over the grey area in Fig. 1, would result in more small scale details, but possibly at the expense of some noise (aliasing). However, one should realize that $\sigma_{0}$ in the grey box is not sampled by a point response function, but oversampled with a field of view (FOV) of approximately $10 \mathrm{~km}$ (along fan beam) by $25 \mathrm{~km}$ (across fan beam). So, with all FOVs centered in a WVC, the integrated FOV (IFOV) for that WVC and beam will be a function extending up to $25 \mathrm{~km}$ outside the WVC in the direction across the fan beam, see Fig. 2 for illustration. This $\sigma_{0}$ extent outside the WVC acts to suppress sampling noise or aliasing, since neighboring WVCs have much overlapping IFOVs for each beam and sample in part the same ocean spatial wind pattern. Fig. 2 also illustrates the concept of $R_{\max }$, in which all full resolution backscatter data (indicated by ellipses in this figure) which have their centre located inside the circle contribute to the averaged WVC backscatter with the same weight.

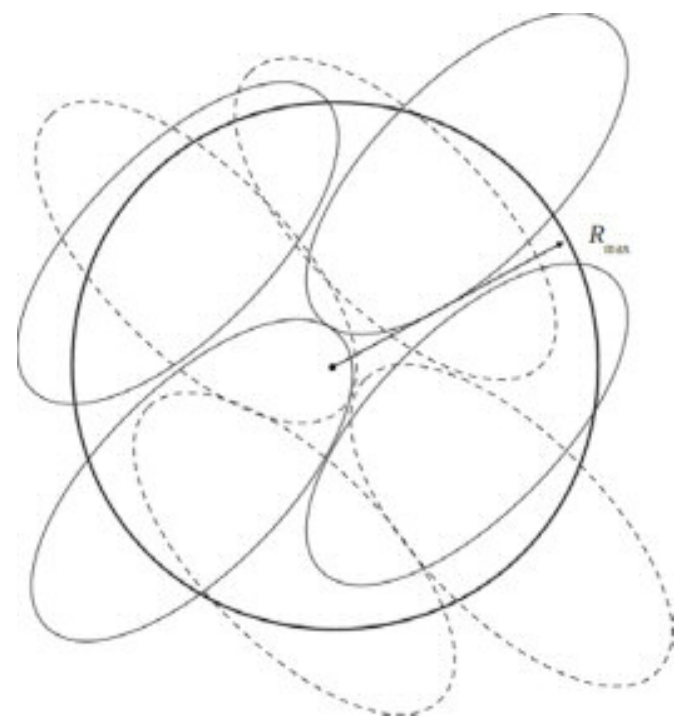

Fig. 2. Schematic illustration of scatterometer sampling. A target WVC (thick solid line, with cut-off radius $R_{\max }$ ) is sampled from two different perspectives (for simplification), with a beam footprint indicated by solid and dashed lines, respectively.

Three different cut-off radii $R_{\max }$ for the backscatter averaging area are considered in this paper and the resulting winds are compared. Based on the validation results (Section IV), the best setting of the cut-off radius is chosen.

\section{TEST DATA}

The validations of the coastal product are done using 6 months of ASCAT full resolution data (1 March 2009 to 31 August 2009) which were kindly provided by the EUMETSAT Data Centre. As described in the previous 
Section, two parameters can be set that influence the characteristics of the final wind product:

(1) The maximum distance $R_{\max }$ from the $12.5 \mathrm{~km} \mathrm{WVC}$ centre to search for full resolution backscatter measurements is set to three different values: $20 \mathrm{~km}, 15 \mathrm{~km}$ and $12.5 \mathrm{~km}$. This yields three data sets which are validated separately. It can be expected that for higher $R_{\max }$ values there will be less noise in the wind product, but the winds will also contain less small-scale details. The goal is to set $R_{\max }$ such that we get a product of comparable quality to the nominal $12.5 \mathrm{~km}$ product in regions far away from the coast.

(2) For the computation of the land contamination a FR measurement land fraction is calculated using all land-sea mask grid points closer than $20 \mathrm{~km}$ from the measurement location. This maximum distance was not changed in this study. The maximum land fraction value was also kept constant at a value of $0.02(2 \%)$. In principle, it would be possible to compute winds even closer to the coast if the exact shape of the radar beam footprints is known, but this has not been the case in this work for the FR input product. Therefore, a safe margin to the coast was kept.

Using the three settings of $R_{\max }$, the 6 months of ASCAT data have been reprocessed. The level $1 \mathrm{~b}$ part (backscatterrelated data) of the $12.5 \mathrm{~km}$ OSI SAF operational wind data was used together with the full resolution data. After the replacement of the (nominal) backscatter data by the averaged (coastal) $\sigma_{0}$ values, the rest of the wind processing is done in the same way as for the nominal products [4] and the level 2 part (wind retrieval related data) of the OSI SAF wind products is overwritten by the coastal winds.

The ASCAT Wind Data Processor (AWDP) version 1.1 (available from the Numerical Weather Prediction Satellite Application Facility, NWP SAF) was used for coastal processing as well, with some minor modifications of the code to produce the three different data sets.

\section{VALIDATION}

\section{A. Comparison with nominal data}

Fig. 3 shows an example of the difference between the ASCAT nominal $12.5 \mathrm{~km}$ and the coastal wind products. It is clear that the coastal product provides winds closer to the coast which yields many more wind vectors, especially in the areas between the islands in this part of the Mediterranean.

Note that, as described in Section II, the three coastal product data sets used in this work have been constructed using a land fraction field containing 400 grid points between the Equator and the Pole. After the processing of the three data sets for this work was finished, ECMWF implemented a land fraction field containing 640 grid points between equator and pole, i.e. with a spacing of approximately $15.6 \mathrm{~km}$ as compared to $25 \mathrm{~km}$. This mask yields ASCAT winds even closer to the coast than in Fig. 3 (right panel). The land fraction grid size is adequate since it is comparable to the radar beam footprint size and since some margin from the coast is kept.
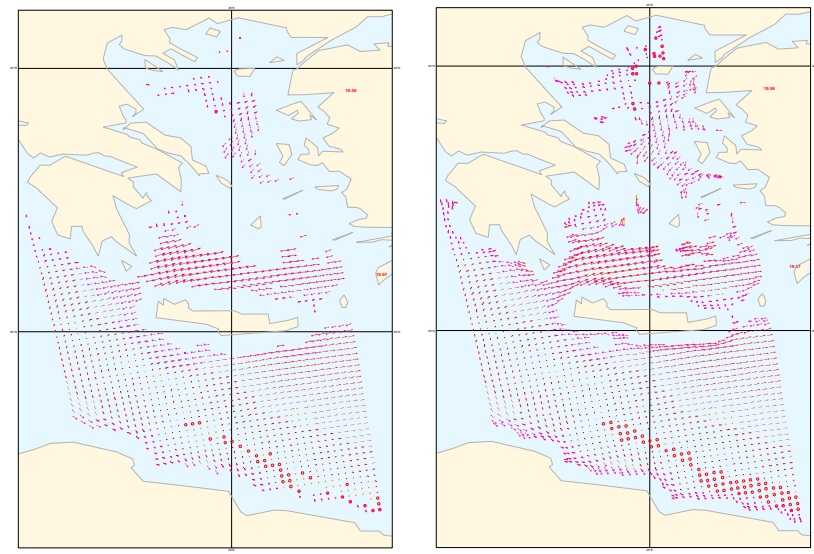

Fig. 3. Example of nominal $12.5 \mathrm{~km}$ ASCAT product (left) and corresponding coastal product with $R_{\max }=15 \mathrm{~km}$ (right) in the eastern part of the Mediterranean at 2 March 2009 19:57 UTC. The purple squares correspond to WVCs where the land flag is set, but where reliable winds can still be computed.
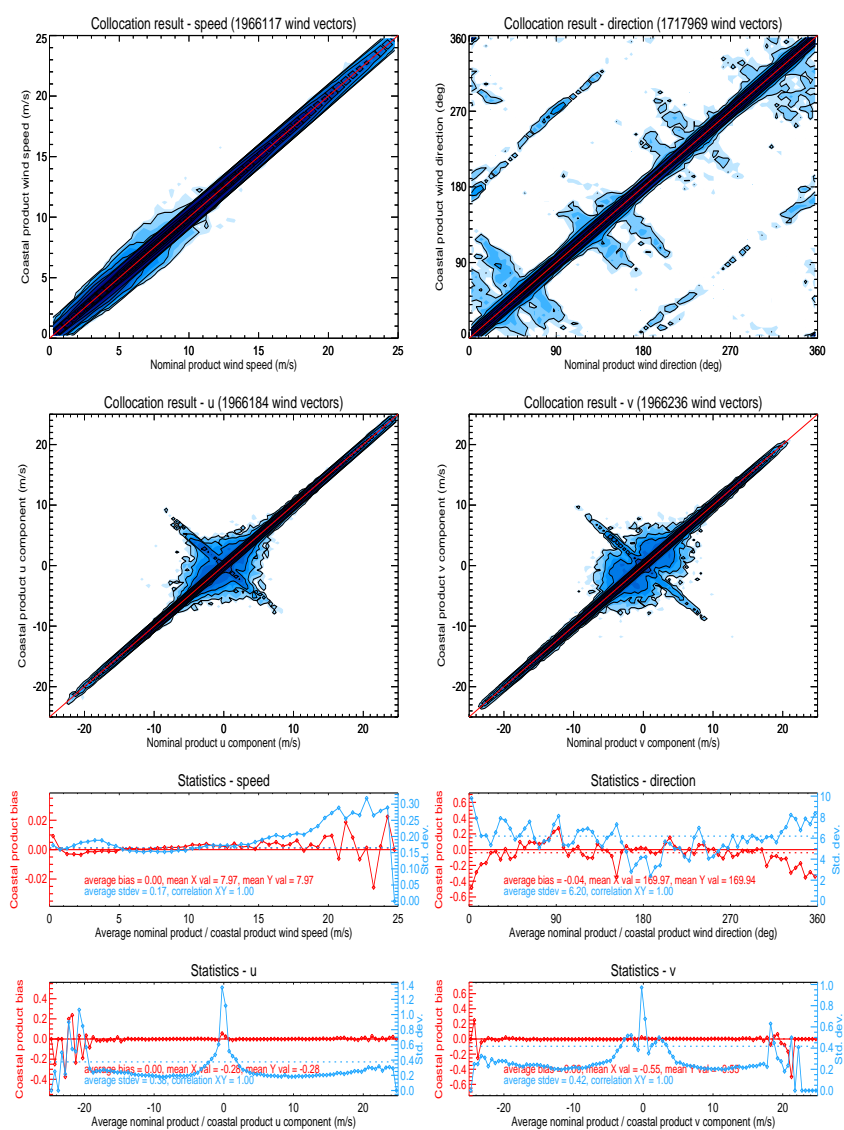

Fig. 4. Two-dimensional histograms of wind speed, direction (w.r.t. wind coming from the North), $u$ and $v$ components of ASCAT coastal product with $R_{\max }=15 \mathrm{~km}$ versus the nominal $12.5 \mathrm{~km}$ product, from 1 March 2009 1:36 to 2 March 2009 1:14 UTC (top panels). The corresponding biases (red) and standard deviations (blue) as a function of the average nominal and coastal scatterometer results are shown in the bottom panels.

Fig. 4 shows two-dimensional histograms of the coastal product with $R_{\max }=15 \mathrm{~km}$ compared with the nominal 12.5 $\mathrm{km}$ data. It is clear from the plots that this coastal product very 
much resembles the nominal product; there is no wind speed bias and the wind component standard deviations (bottom panels) are quite small, $0.38 \mathrm{~m} / \mathrm{s}$ for the $u$ component and 0.42 $\mathrm{m} / \mathrm{s}$ for the $v$ component. Most of the deviations appear to be connected with differences in ambiguity selection resulting in winds $180^{\circ}$ apart, mostly at the lower wind speeds (see $u$ and $v$ plots). Whether these changes are an improvement or not may be concluded from buoy verification and spatial consistency checks as described later on in this manuscript. The corresponding results for the coastal products with $R_{\max }=$ $12.5 \mathrm{~km}$ and $R_{\max }=20 \mathrm{~km}$ are not shown here, since they very much resemble those in Fig. 4 . The product with $R_{\max }=15 \mathrm{~km}$ yields the lowest wind component standard deviations but the differences between the three coastal products are small, i.e., less than $0.05 \mathrm{~m} / \mathrm{s}$. The Hamming filter as shown in Fig. 1 has a half width at half maximum of $12.5 \mathrm{~km}$ in the cross track and along track directions. It is applied as a square filter and its effective filter area is $25 \mathrm{~km} \times 25 \mathrm{~km}$. We use a circular filter which has, for the same diameter (as $\mathrm{x}, \mathrm{y}$ box size), a $21.4 \%$ smaller area than the Hamming filter. Moreover, convolution with the spatially distributed radar footprint sizes of about $10 \mathrm{~km}$ by $25 \mathrm{~km}$ has a somewhat different effect on a box and Hamming filter window. Hence it is understandable that a box filtering using a circular cut-off of $15 \mathrm{~km}$ from the WVC centre will have spatial properties closest to the nominal $12.5 \mathrm{~km}$ product.

\section{B. Buoy validations}

In this Section, scatterometer wind data are compared with in situ buoy wind measurements. The buoy wind data are distributed through the Global Telecommunication System (GTS) and have been retrieved from the ECMWF MARS archive. The buoy data are quality controlled and (if necessary) blacklisted by ECMWF [5]. We used two sets of buoy data:

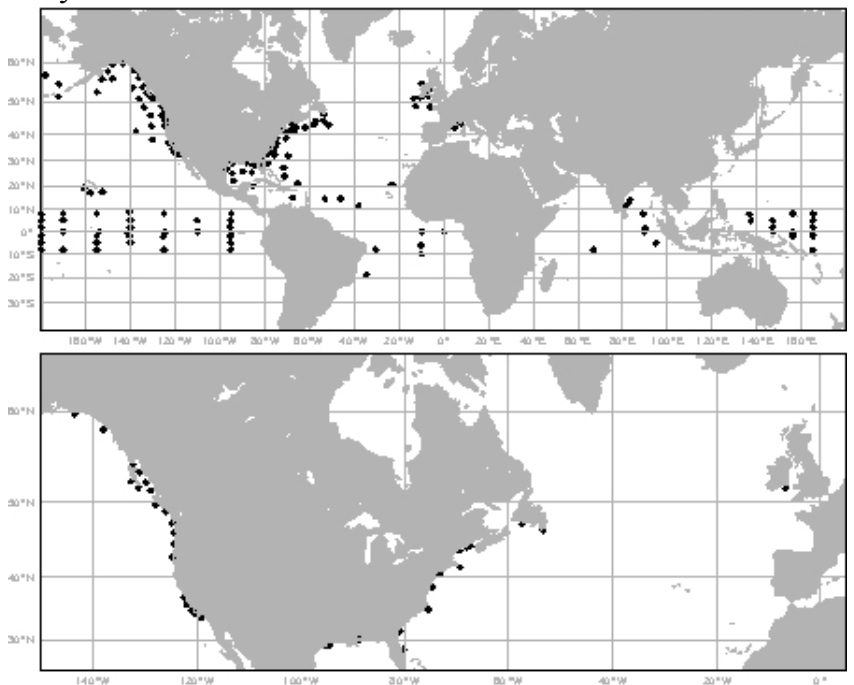

Fig. 5. Locations of the non-coastal (top) and coastal (bottom) moored buoys used in the comparisons.

(1) A set of approximately 150 moored non-coastal buoys spread over the oceans (most of them in the tropical oceans and near Europe and North America) which are also used in the buoy validations that are routinely performed for the OSI $\mathrm{SAF}$ wind products (see the links on http://www.knmi.nl/scatterometer/osisaf/). Most of these buoys are located more than 50 kilometers away from the coast.

(2) A set of approximately 35 moored coastal buoys which are located between approximately 10 and 50 kilometers from the coast. We used the web site of the National Data Buoy Centre (http://www.ndbc.noaa.gov/) to search for buoys located near the coast.

A buoy cannot be present both in data set (1) and (2). See Fig. 5 for the locations of the buoys used in the comparisons. A scatterometer wind and a buoy wind measurement are considered to be collocated if the distance between the Wind Vector Cell (WVC) centre and the buoy location is less than the WVC spacing divided by $\sqrt{2}$ and if the acquisition time difference is less than 30 minutes.

The buoy winds are measured hourly by averaging the wind speed and direction over 10 minutes. The real winds at a given anemometer height have been converted to $10 \mathrm{~m}$ equivalent neutral winds using the LKB model [5], [6] in order to enable a good comparison with the $10 \mathrm{~m}$ scatterometer winds.

\section{1) Results in non-coastal areas}

In Table I we compare the $12.5 \mathrm{~km}$ nominal and coastal products with various settings of $R_{\max }$ in the regions far away from the coast. The wind speed bias, the standard deviations of the $u$ and $v$ wind components and the vector RMS are shown in this table.

TABLE I

BUOY COLLOCATIONS IN NON-COASTAL AREAS

\begin{tabular}{llrrrrr}
\hline \hline & $12.5 \mathrm{~km}$ product & $\begin{array}{r}\text { \# wind } \\
\text { vectors }\end{array}$ & $\begin{array}{r}\text { speed } \\
\text { bias }\end{array}$ & $\begin{array}{r}\text { stdev } \\
u\end{array}$ & $\begin{array}{r}\text { stdev } \\
v\end{array}$ & $\begin{array}{r}\text { RMS } \\
\text { vecor }\end{array}$ \\
\hline 1 & Nominal & 14513 & -0.28 & 1.46 & 1.58 & 2.21 \\
2 & $R_{\max }=20 \mathrm{~km}$ & 15373 & -0.29 & 1.43 & 1.56 & 2.17 \\
3 & $R_{\max }=15 \mathrm{~km}$ & 15476 & -0.29 & 1.46 & 1.59 & 2.21 \\
4 & $R_{\max }=12.5 \mathrm{~km}$ \\
\hline 5 & $\begin{array}{l}\text { Nominal, collocated } \\
\text { data set }\end{array}$ & 15498 & -0.29 & 1.48 & 1.61 & 2.24 \\
6 & $\begin{array}{l}R_{\max }=20 \mathrm{~km}, \\
\text { collocated data set } \\
7\end{array}$ & 12761 & -0.28 & 1.43 & 1.56 & 2.17 \\
$\begin{array}{l}R_{\max }=15 \mathrm{~km}, \\
\text { collocated data set }\end{array}$ & 12761 & -0.29 & 1.44 & 1.54 & 2.17 \\
8 & $\begin{array}{l}R_{\max }=12.5 \mathrm{~km}, \\
\text { collocated data set }\end{array}$ & 12761 & -0.29 & 1.45 & 1.57 & 2.19 \\
\hline \hline
\end{tabular}

Buoy collocation results of ASCAT $12.5 \mathrm{~km}$ nominal and coastal wind products from March to August 2009 in non-coastal areas. The collocated data set (lines 5-8) refers to those scatterometer and buoy winds (corresponding to a certain buoy location and time) which are present in all four products.

The entries 1 to 4 of the table show that the coastal products yield more buoy collocations (\# wind vectors) than the nominal product, and that the number of collocations increases slightly with decreasing $R_{\max }$. This increase cannot be connected to the increase of the number of wind vectors in coastal areas (since Table I only contains open ocean results) so it must be due to a decrease in the number of quality 
controlled (i.e., rejected) wind vectors with the decrease of $R_{\max }$. The smaller the area of backscatter averaging, the smaller the wind variability in the WVC area. Large subWVC wind variability is known to result in backscatter triplets far away from the Geophysical Model Function [7] with an increased rate of rejection by the quality control step [10]. The wind speed bias, wind component standard deviations and vector RMS of all four products are fairly constant although the component standard deviations and vector RMS slightly increase with decreasing $R_{\max }$.
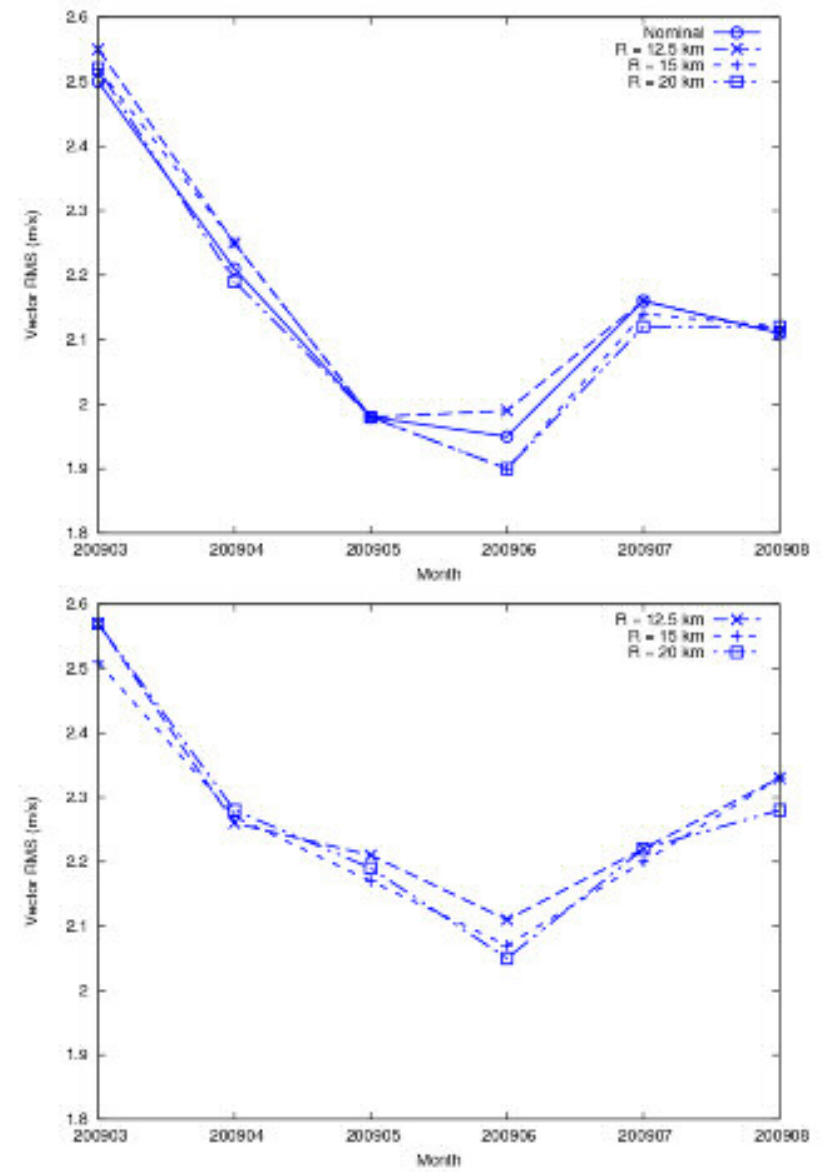

Fig. 6. Top: buoy collocation results (wind vector RMS) of ASCAT 12.5 $\mathrm{km}$ nominal and coastal wind products from March to August 2009 in noncoastal areas per month. These are the detailed results of lines 5-8 of Table 1. The number of wind vectors is between 2019 and 2338 per month.

Bottom: buoy collocation results (wind vector RMS) of ASCAT coastal wind products from March to August 2009 in coastal areas per month. These are the detailed results of lines 4-6 of Table 2. The number of wind vectors is between 609 and 891 per month.

Entries 5 to 8 of Table I show the results for the common set of WVCs present in all four products. It appears that all products have comparable quality, but with a small increase of the wind component standard deviations and vector RMS of the product with $R_{\max }=12.5 \mathrm{~km}$. The coastal product with $R_{\max }=15 \mathrm{~km}$ shows results more or less comparable to those of the nominal product for the common points. In order to check the significance of these conclusions, we have broken up the statistics of entries 5 to 8 of Table I into monthly results in Fig. 6 (top). It appears from this figure that for almost all months, there is a slight increase of vector RMS with decreasing $R_{\max }$, despite the large vector RMS variations over the months. The vector RMS values of the nominal product are comparable to those of the coastal products.

\section{2) Results in coastal areas}

In Table II we compare the coastal products with various settings of $R_{\max }$ in the coastal regions (less than $50 \mathrm{~km}$ from the coast). The wind speed bias, the standard deviations of the $\mathrm{u}$ and $\mathrm{v}$ wind components and the wind vector RMS are shown in this table.

TABLE II

BUOY COLLOCATIONS IN COASTAL AREAS

\begin{tabular}{llrrrrr}
\hline \hline & $12.5 \mathrm{~km}$ product & $\begin{array}{r}\text { \# wind } \\
\text { vectors }\end{array}$ & $\begin{array}{r}\text { speed } \\
\text { bias }\end{array}$ & $\begin{array}{r}\text { stdev } \\
u\end{array}$ & $\begin{array}{r}\text { stdev } \\
v\end{array}$ & $\begin{array}{r}\text { RMS } \\
\text { vecor }\end{array}$ \\
\hline 1 & $R_{\max }=20 \mathrm{~km}$ & 4752 & -0.23 & 1.54 & 1.59 & 2.29 \\
2 & $R_{\max }=15 \mathrm{~km}$ & 4768 & -0.22 & 1.54 & 1.61 & 2.30 \\
3 & $R_{\max }=12.5 \mathrm{~km}$ & 4789 & -0.23 & 1.57 & 1.60 & 2.32 \\
\hline 4 & $\begin{array}{l}R_{\max }=20 \mathrm{~km}, \\
\text { collocated data set }\end{array}$ & 4596 & -0.23 & 1.51 & 1.57 & 2.26 \\
5 & $\begin{array}{l}R_{\max }=15 \mathrm{~km}, \\
\text { collocated data set } \\
R_{\max }=12.5 \mathrm{~km}, \\
\text { collocated data set }\end{array}$ & 4596 & -0.24 & 1.51 & 1.57 & 2.25 \\
\hline \hline
\end{tabular}

Buoy collocation results of ASCAT coastal wind products from March to August 2009 in coastal areas. The collocated data set (lines 4-6) refers to those scatterometer and buoy winds (corresponding to a certain buoy location and time) which are present in all three products.

The number of buoy collocations (\# wind vectors) slightly increases with decreasing $R_{\max }$, like in the non-coastal case (see entries 1 to 3 in Table II). This may again be connected to the decrease of wind variability when backscatter averaging is done over a smaller area, but in this case we also observe that we get some more wind data near the coast with a smaller value of $R_{\max }$. This can be understood since it is easier to fit WVCs without land contamination in bays and between isles when the backscatter averaging area is somewhat smaller.

Like in the non-coastal areas, the wind component standard deviations and vector RMS slightly increase with decreasing $R_{\text {max }}$. When we consider the common set of WVCs present in all three coastal products (entries 4 to 6 in Table II), the product with $R_{\max }=12.5 \mathrm{~km}$ again appears slightly degraded with respect to the two other products. Like in the non-coastal areas, we have broken up the statistics of entries 4 to 6 of Table II into monthly results in Fig. 6 (bottom). Again we observe a slight increase of vector RMS with decreasing $R_{\max }$, although the trend is less clear here, probably due to the small amount of monthly collocations.

The wind speed bias in the coastal areas is approximately $-0.23 \mathrm{~m} / \mathrm{s}$ as compared to $-0.29 \mathrm{~m} / \mathrm{s}$ in the non-coastal areas (see Table I). If the backscatter averaging took too many land contaminated full resolution $\sigma_{0}$ values into account, the averaged WVC backscatter would be increased since land areas yield higher radar reflectivities. This would result in significantly higher wind speed biases near the coast which is clearly not the case. In this sense the box backscatter averaging and land screening as described in this work proves 
to be adequate. We note furthermore that wind speed biases are seasonally dependent and that the biases found here over 6 months are within expectation.

\section{Spectral analysis}

Wind component spectra are a means to detect noise and assess the relative amount of small scale information in a wind product [8]. Fig. 7 shows the wind spectra of the nominal
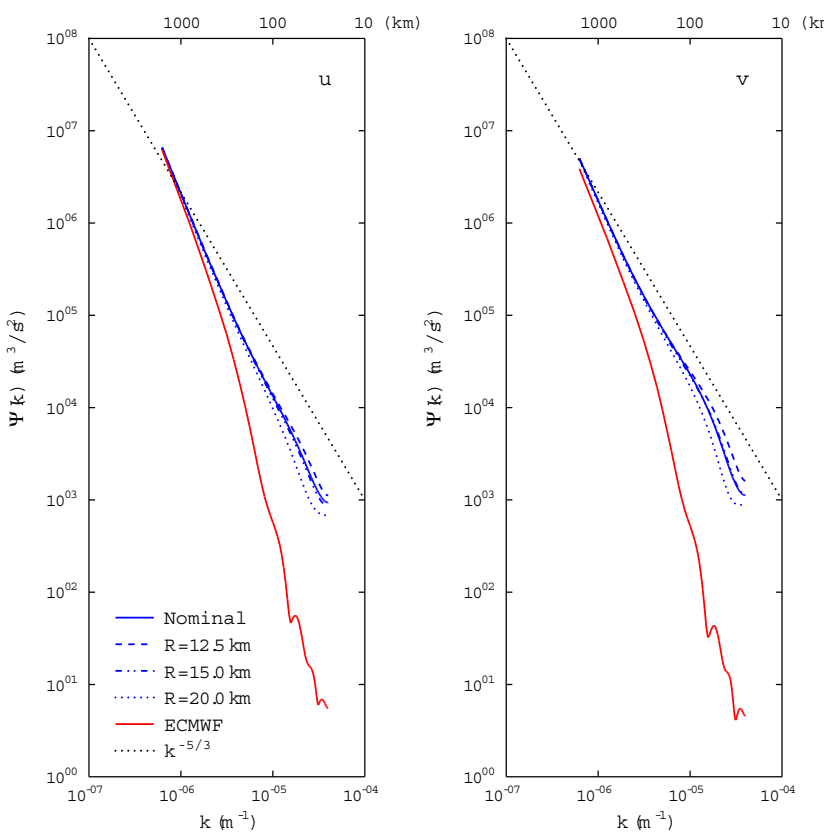

Fig. 7. Wind spectra of ASCAT nominal and coastal wind products. The results for the $\mathrm{u}$ wind components are shown in the left hand side plot and for the $\mathrm{v}$ wind component in the right hand side plot. The results are for the nominal product and for the coastal products with different $R_{\max }$ settings. The spectra of the interpolated ECMWF global model forecasts, as present in the wind products, are also shown. The plots cover the period of 1 to $31 \mathrm{March}$ 2009.

ASCAT product and the three flavors of the coastal product. It appears that all products have comparable spectra with a slope close to the $k^{-5 / 3}$ spectrum which is shown as a black dotted line in the plots. According to a host of measurements, among which from aircraft [9], and the 3D turbulence theory of Kolmogorov, the wind spectra follow such spectra for scales smaller than about $500 \mathrm{~km}$ (spatial frequency $2 \cdot 10^{-6} \mathrm{~m}^{-1}$ ). The coastal product with $R_{\max }=12.5 \mathrm{~km}$ yields the highest values at high spatial frequencies indicating the presence of many small scales in the winds. The spectrum of the $R_{\max }=15 \mathrm{~km}$ product is closest to the one of the nominal $12.5 \mathrm{~km}$ product, the $R_{\max }=20 \mathrm{~km}$ product shows the least small scale information (lowest values in the spectrum tail). None of the spectra shows significant flattening at high spatial frequencies which indicates that there is little white noise in the winds.

\section{CONCLUSIONS AND OUTLOOK}

Three different ASCAT coastal products, with backscatter averaging cut-off radii $R_{\max }=20,15$ and $12.5 \mathrm{~km}$, have been validated. All three provide wind quality well within the OSI $\mathrm{SAF}$ product requirements (wind speed bias less than $0.5 \mathrm{~m} / \mathrm{s}$ and wind component RMS better than $2.0 \mathrm{~m} / \mathrm{s}$ ), both in noncoastal and coastal regions.

The coastal product based on backscatter averaging cut-off radius $R_{\max }=15 \mathrm{~km}$ most closely resembles the nominal 12.5 $\mathrm{km}$ product, both with respect to the wind component standard deviations and to the shape of the wind component spectra. The coastal product provides slightly more winds after quality control than the nominal product, probably due to the smaller spatial averaging extent, therefore smaller ocean wind variability and consequently greater consistency of the backscatter triplet.

We note that the required characteristics of the wind products are application dependent. This is, in applications interested in high wind gradients, such as near tropical cyclones, even higher resolution products than the ones presented here may be worthwhile, since intense small-scale details may become visible. The limited amount of noise visible in the $12.5 \mathrm{~km}$ coastal products is very encouraging in this respect.

Although the current coastal products perform very well, some aspects need further elaboration. The first aspect lies in an improved quality control, more suitable for the coastal product. In cases with variable winds (fronts, centers of lows, hurricanes), box processing results in more consistent backscatter triplets than Hamming filtering, i.e., closer to the CMOD5.N Geophysical Model Function in measurement space. Along the same lines, one may expect lower geophysical noise at the relatively more variable spatial backscatter conditions at low winds [7]. The box processing appears also less problematic in the ambiguity removal, thus resulting in spatially more coherent wind patterns. Since the spatial consistency check in the ambiguity removal step is most active in variable wind conditions, this asset of the coastal processing may be another sign of physically more robust processing. However, these aspects need further detailed elaboration in order to increase our understanding of the differences between Hamming and box processing.

It would also be useful to further investigate the influence of $R_{\max }$ and the maximum allowed land fraction on the wind quality. In this study, we only used three $R_{\max }$ values quite close together and only one maximum land fraction. This yields wind product with quite comparable quality; it will be worthwhile to explore more extreme parameter settings in search for their limiting values.

Finally, it may be worthwhile to improve the land masking in regions close to the coast using more detailed knowledge of the radar beam footprints of fore, mid and aft beams and a land-sea mask of higher resolution.

\section{ACKNOWLEDGMENT}

We are grateful to Jean Bidlot of ECMWF for helping us with the buoy data retrieval and quality control. EUMETSAT kindly provided/provides the ASCAT full resolution data from the Data Centre archive and in near-real time. Jur Vogelzang 
of KNMI provided the wind spectra plots.

\section{REFERENCES}

[1] Figa-Saldaña, J., Wilson, J.J.W., Attema, E., Gelsthorpe, R., Drinkwater, M.R., Stoffelen, A., "The Advanced Scatterometer (ASCAT) on the meteorological operational (MetOp) platform: A follow on for European wind scatterometers", Can. .J. Remote Sensing, vol.28, no.3, pp. 404412, 2002.

[2] EUMETSAT, "ASCAT products guide",

EUM/OPS-EPS/MAN/04/0028, available on http://www.eumetsat.int, 2011.

[3] Owen, M.P., Long, D.G. "Land-Contamination Compensation for QuikSCAT Near-Coastal Wind Retrieval", IEEE Trans. Geosci. Remote Sens., vol. 47, pp. 839 - 850, 2009, doi: 10.1109/TGRS.2008.2005633.

[4] OSI SAF, "ASCAT Wind Product User Manual", $\mathrm{SAF} / \mathrm{OSI} / \mathrm{CDOP} / \mathrm{KNMI} / \mathrm{TEC} / \mathrm{MA} / 126$, available on http://www.osi-saf.org, 2011.

[5] Bidlot J., Holmes, D., Wittmann, P., Lalbeharry, R., and Chen, H., "Intercomparison of the performance of operational ocean wave forecasting systems with buoy data", Wea. Forecasting, vol. 17, pp. $287-$ 310, 2002.

[6] Liu, W.T., Katsaros, K.B., and Businger, J.A., "Bulk parameterization of air-sea exchanges of heat and water vapor including the molecular constraints in the interface" J. Atmos. Sci., vol. 36, pp 1722-1735, 1979.

[7] Portabella, M. and Stoffelen, A., "Scatterometer backscatter uncertainty due to wind variability", IEEE Trans. on Geosci. and Remote Sens., vol. 44, no. 11, pp 3356-3362, 2006.

[8] Vogelzang, J., Stoffelen, A., Verhoef, A., and Figa-Saldaña, J., "On the quality of high-resolution scatterometer winds", J. Geophys. Res., 116, C10033, 2011, doi:10.1029/2010JC006640.

[9] Nastrom, G.D., Gage, K.S., and Jasperson, W.H., "Kinetic Energy Spectrum of Large and Mesoscale Processes", Nature, vol. 310, 36-38, 1984.

[10] Portabella, M., Stoffelen, A., Verhoef, A., and Verspeek, J., "A new method for improving ASCAT wind quality control," IEEE Geosc. and Rem. Sens. Lett., submitted in June 2011.

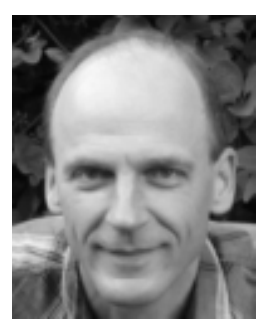

Anton Verhoef was born on December 10, 1964 in The Netherlands. He received his M.Sc. degree in physics from the Rijksuniversiteit Groningen, The Netherlands in 1989 and his Ph.D in Solid State Physics at the Rijksuniversiteit Groiningen in 1994. $\mathrm{He}$ is currently with the Royal Netherlands Meteorological Institute (KNMI) and working on scatterometry processing software development, data validation, quality monitoring and user services.

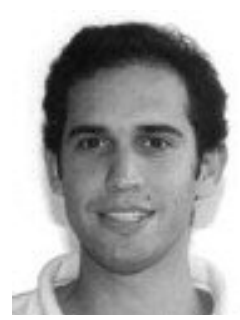

Marcos Portabella was born on October 14, 1970 in Spain. He received the B.Sc. degree in Physics in 1994 from the University of Barcelona, Spain; the M.Sc. in Remote Sensing in 1995 from the Institute of Space Studies of Catalonia, Spain; and the Ph.D. degree in Physics in 2002, from the University of Barcelona, Spain.

$\mathrm{He}$ is currently with the Unidad de Tecnología Marina (UTM - CSIC), Barcelona, Spain, working on satellite remote sensing. In particular, he is involved in scatterometry and L-band radiometry.

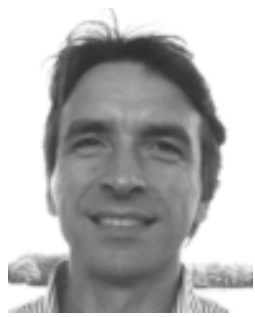

Ad Stoffelen was born on February 25, 1962, in The Netherlands. He received his M.Sc. degree in physics from the Technical University of Eindhoven, The Netherlands, in 1987 and his Ph.D in Meteorology on scatterometry at the University of Utrecht, the Netherlands.

$\mathrm{He}$ is working at KNMI and responsible for the ASCAT wind products. He is also deeply involved in the European Space Agency ADM-Aeolus Doppler Wind Lidar mission. 